\title{
Article \\ PRP4 Promotes Skin Cancer by Inhibiting Production of Melanin, Blocking Influx of Extracellular Calcium, and Remodeling Cell Actin Cytoskeleton
}

\author{
Muhammad Bilal Ahmed, Salman U1 Islam (D) and Young Sup Lee *(D)
}

check for

updates

Citation: Ahmed, M.B.; Islam, S.U.; Lee, Y.S. PRP4 Promotes Skin Cancer by Inhibiting Production of Melanin, Blocking Influx of Extracellular Calcium, and Remodeling Cell Actin Cytoskeleton. Int. J. Mol. Sci. 2021, 22, 6992. https://doi.org/10.3390/ ijms22136992

Academic Editors: Takeo Nakanishi and Zhe-Sheng (Jason) Chen

Received: 21 May 2021

Accepted: 23 June 2021

Published: 29 June 2021

Publisher's Note: MDPI stays neutra with regard to jurisdictional claims in published maps and institutional affiliations.

Copyright: (c) 2021 by the authors. Licensee MDPI, Basel, Switzerland. This article is an open access article distributed under the terms and conditions of the Creative Commons Attribution (CC BY) license (https:// creativecommons.org/licenses/by/ $4.0 /)$.
BK21 FOUR KNU Creative Bioresearch Group, School of Life Sciences, Kyungpook National University, Daegu 41566, Korea; muhammad786@knu.ac.kr (M.B.A.); salman2013@knu.ac.kr (S.U.I.)

* Correspondence: yselee@knu.ac.kr; Tel.: +82-53-950-6353; Fax: +82-53-943-2762

\begin{abstract}
Pre-mRNA processing factor 4B (PRP4) has previously been shown to induce epithelialmesenchymal transition (EMT) and drug resistance in cancer cell lines. As melanin plays an important photoprotective role in the risk of sun-induced skin cancers, we have investigated whether PRP4 can induce drug resistance and regulate melanin biosynthesis in a murine melanoma (B16F10) cell line. Cells were incubated with a crucial melanogenesis stimulator, alpha-melanocyte-stimulating hormone, followed by transfection with PRP4. This resulted in the inhibition of the production of melanin via the downregulation of adenylyl cyclase-cyclic adenosine $3^{\prime}, 5^{\prime}$-monophosphate (AC)(cAMP)-tyrosinase synthesis signaling pathway. Inhibition of melanin production by PRP4 leads to the promotion of carcinogenesis and induced drug resistance in B16F10 cells. Additionally, PRP4 overexpression upregulated the expression of $\beta$-arrestin 1 and desensitized the extracellular calciumsensing receptor (CaSR), which in turn, inhibited the influx of extracellular $\mathrm{Ca}^{2+}$ ions. The decreased influx of $\mathrm{Ca}^{2+}$ was confirmed by a decreased expression level of calmodulin. We have demonstrated that transient receptor potential cation channel subfamily $\mathrm{C}$ member 1 was involved in the influx of CaSR-induced $\mathrm{Ca}^{2+}$ via a decreasing level of its expression. Furthermore, PRP4 overexpression downregulated the expression of $\mathrm{AC}$, decreased the synthesis of cAMP, and modulated the actin cytoskeleton by inhibiting the expression of Ras homolog family member A (RhoA). Our investigation suggests that PRP4 inhibits the production of melanin in B16F10 cells, blocks the influx of $\mathrm{Ca}^{2+}$ through desensitization of CaSR, and modulates the actin cytoskeleton through downregulating the AC-cAMP pathway; taken together, these observations collectively lead to the promotion of skin carcinogenesis.
\end{abstract}

Keywords: PRP4; melanocyte; cAMP; calcium-sensing receptor; actin cytoskeleton; drug resistance

\section{Introduction}

The melanoma cell line B16F10 can produce melanin and displays metastatic behaviors. These cells are widely used to study melanogenesis and depigmentation [1], tumor metastasis [2], and cytotoxicity measurements of various substances in skin models [3]. Melanogenesis is a complex process regulated by enzymatic cascades, including tyrosinase, tyrosinase-related protein (TRP)-1, and their transcription factors like microphthalmiaassociated transcription factor (MITF), cAMP response element-binding protein (CREB), and extracellular-regulated kinase (ERK) [4]. The most crucial hormone in stimulating melanogenesis is alpha-melanocyte stimulating hormone $(\alpha-\mathrm{MSH})$, which binds and induces MITF. $\alpha$-MSH binds to melanocortin 1 receptors, which produces cAMP, and cAMP phosphorylates the CREB transcription factor, which in turn promotes MITF activation. MITF binds to the promoter regions of melanin production genes and positively regulates their transcription of TRP-1 and tyrosinase [5-7]. As previously identified, melanin has a photoprotective role and decreases the risk of sun-induced skin cancers [8,9]. It is also 
reported to serve as a physical barrier that scatters ultraviolet radiations, and as an absorbent filter that reduces the penetration of these radiations through the epidermis [10]. Melanosomes in dark skin show resistance to lysosomal degradation and remain intact throughout the epidermal layers. Moreover, they form supranuclear caps in keratinocytes and melanocytes, and protect against ultraviolet radiations-induced damage [11,12].

Extracellular calcium-sensing receptor (CaSR) is a G-protein-coupled receptor (GPCR) predominantly expressed in the kidneys and parathyroids, where it regulates the secretion of parathyroid hormone and renal tubular calcium reabsorption [13]. The expression of CaSR has also been reported in other tissues including lung, heart, skin, brain, pancreas, intestine, bone, bone marrow, lens epithelium, and thyroid, where its role remains yet to be defined [14]. When a ligand binds to CaSR, it stimulates the release of $\mathrm{Ca}^{2+}$ from intracellular stores via activation and accumulation of phospholipase $C$ and inositol 1,4,5-trisphosphate, respectively, followed by an influx of $\mathrm{Ca}^{2+}$ [14].

Previous studies have demonstrated that CaSR, which is expressed on the surface, may undergo endocytosis, which is initiated with phosphorylation by protein kinase $C$ or $G$ protein-coupled receptor kinase (GRKs) $[15,16]$. This process involves $\beta$-arrestins (ARRBs) and is facilitated by Ras-related protein Rab-7a, Ras-related protein Rab-11A, and adaptor protein-2 [17-19]. CaSR is translocated to the lysosomes for degradation after endocytosis or is recycled to the cell membrane, which contributes to the receptor resensitization $[20,21]$. ARRBs are ubiquitously expressed proteins that play a crucial role in the desensitization and internalization of most GPCRs [22]. Min Pi et al. analyzed luciferase activity in HEK293 cells that were cotransfected with rat CaSR, and an SRE-luciferase reporter constructs in the presence or absence of ARRB1 and ARRB2. They reported that ARRB isoforms downregulate the level of CaSR-induced luciferase activity [16]. Also, interaction between ARRB1 and the CaSR has been shown in mammalian cells by coimmunoprecipitation experiments [16]. It has also been observed that overexpression of both ARRB1 and ARRB2 will have a negative influence on CaSR-mediated inositol phosphate production in GripTite293 cells [15].

$\mathrm{Ca}^{2+}$ influx through store-operated channels has been shown to be induced by CaSR, which, in many cases, has been identified as the transient receptor potential (TRP) family members [23]. Yassine El Hiani et al. reported that ERK and transient receptor potential canonical 1 (TRPC1) were required for CaSR-stimulated MCF-7 breast cancer cell proliferation [24]. In endothelial cells, it is probable that TRPC1 is a contributor to the formation of store operated $\mathrm{Ca}^{2+}$ channels [25].

Cyclic adenosine $3^{\prime}, 5^{\prime}$-monophosphate (cAMP) mediates diverse effects in cytoskeletal dynamics, cell migration, and cell adhesion [26,27]. Elevation of cAMP and activation of PKA have been reported to be involved in microfilament assembly [28], mammary epithelial cell migration on laminin [29], formation of filopodia and lamellipodia in response to follicle-stimulating hormone [30], and activation of Cdc42 and Rac [31,32]. It has been suggested that inhibition of Rho is involved in mediating the effects of cAMP and PKA on actin-based movement and morphology [33-35].

The protein, PRP4, was first identified from screens designed to isolate genes essential for pre-mRNA splicing processes in Schizosaccharomyces pombe, which reported that mutations of fission yeast PRP4 kinase caused the accumulation of pre-mRNA species [36]. Human PRP4 encodes a 1007-amino acid protein containing an N-terminal 340-amino acid Arg/Ser-rich domain, which is commonly found in pre-mRNA splicing factors [37]. It has been reported that in addition to RS domain, PRP4 contains a kinase domain, which shares homology with cyclin-dependent kinases and mitogen-activated protein kinases [38,39]. It is noteworthy that kinase domain is absent in other pre-mRNA splicing factors. Mutations in PRP4 result in pre-mRNA accumulation and in an impaired G1/S transition during the cell cycle [40]. Studies on PRP4 have demonstrated its diverse effects on kinases, transcription factors, chromatin remodeling factors, spindle checkpoint proteins, and cancer cell growth [37,41-43]. In our previous study, we have shown that PRP4 is involved in the promotion of drug resistance in cancer cell lines by inducing changes to 
the cell cytoskeletal architecture and therefore induce epithelial-mesenchymal transition (EMT) [44]. In this current study, we have investigated the regulatory effect of PRP4 on melanin production in B16F10 cells and observed that PRP4 overexpression inhibited the production of melanin. In addition, PRP4 increased the ARRB1-induced desensitization of CaSR, which subsequently decreased the influx of $\mathrm{Ca}^{2+}$ and downregulated the activity of calmodulin. Furthermore, cAMP signaling was inhibited by PRP4 overexpression altering the morphology of B16F10. Our investigation suggests that PRP4 has an important role in regulating the morphological and migratory characteristics of B16F10 cells and may lead to the promotion of skin melanoma through the reduction of melanin production.

\section{Results}

\subsection{PRP4 Inhibits the Production of Melanin in B16F10 Cells and Promotes Skin Cancer}

In our previous investigations, we conducted in vitro studies and reported that PRP4 participates in the development of drug resistance in cancer cell lines [44,45]. In the current investigation, we analyzed the role of PRP4 in vivo using a subcutaneous xenotransplant tumor model by injecting B16F10 cells into BALB/c-n mice. Briefly, parental B16F10 cells are injected on the left, while PRP4-transfected B16F10 cells are injected on the right (according to the left and right of the photo in Figure 1A). Tumor sizes were regularly measured at 3- or 4-day intervals until 50 days post implantation. PRP4-transfected B16F10 cells show enhanced tumor growth relative to parental B16F10 cells, and body weight (average weight $=22.5 \mathrm{~g}$ ) was not affected (Figure $1 \mathrm{~A}$ ). Tumor volume was measured according to the formula described in Materials and Methods and presented in a bar graph. We were curious to find the mechanism through which PRP4 promoted skin cancer, therefore, the effect of PRP4 on the melanin content of B16F10 cells was also investigated in this study. The $\alpha$-MSH binding to melanocortin 1 receptor (MC1R) activates the AC that increases the cAMP levels, which subsequently activates MITF $[46,47]$. MITF binds to the promoter regions of melanin production genes, TRP-1 and tyrosinase, and positively regulates their transcription [5-7]. In this study, to begin we investigated the PRP4 regulatory effect on the production of melanin in B16F10 cells by treating them with $\alpha-\mathrm{MSH}$, followed by PRP4/siRNA-PRP4 transfection. We observed that PRP4 overexpression blocked the $\alpha$-MSH-induced melanin production in B16F10 cells, whereas siRNA-PRP4 reversed the inhibitory effect of PRP4 (Figure 1B). We further analyzed the mRNA and protein levels of tyrosine, which were both downregulated by the overexpression of PRP4 (Figure 1C-F). Our data indicate that PRP4 may decrease the production of melanin in B16F10 cells by downregulating AC-cAMP-MITF-tyrosinase signaling pathway, which subsequently leads to the promotion of skin cancer.

\subsection{PRP4 Regulates ARRB1-CaSR Pathway}

PRP4 was overexpressed in B16F10 cells by transfecting cells with PRP4 expressing plasmid at $2.5 \mu \mathrm{g}$ and $5 \mu \mathrm{g}$ concentration (Figure 2A,B); the latter produced the optimum expression (1.31-fold and 3.80-fold increase at mRNA and protein levels, respectively) and was selected for continuing experiments. We analyzed the effect of PRP4 overexpression upon ARRB1 expression. PRP4 overexpression significantly increased ARRB1 (1.55-fold) at the mRNA level (Figure 2A) and increased the protein level of ARRB1 (2.67-fold) as detected by Western blot (Figure 2B). Previously, it has been shown that ARRB1 induces the desensitization of CaSR, which is continuously exposed to $\mathrm{Ca}^{2+}$, and yet remains very sensitive to even a small change in serum calcium. Desensitization of CaSR may be an important control point for regulating CaSR signaling [16]. To link the ARRB1-CaSR pathway with PRP4, we conducted RT-PCR as well as QPCR, which demonstrated that PRP4 induced the desensitization of CaSR by upregulating ARRB1 (Figure 2C,D). Similar findings were observed through Western blotting (Figure 2E). We also analyzed the mRNA levels of calmodulin, which were interestingly downregulated by PRP4 (Figure 2F). 
A
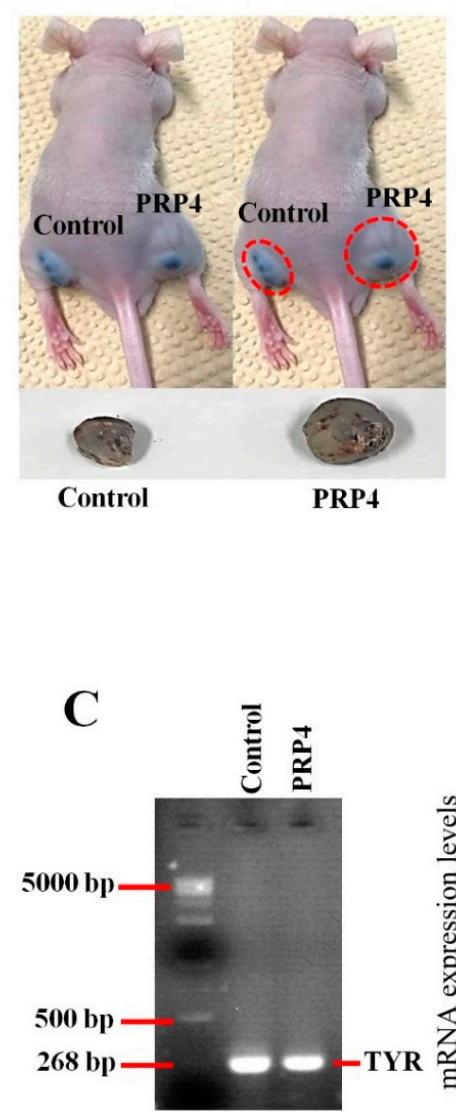

E

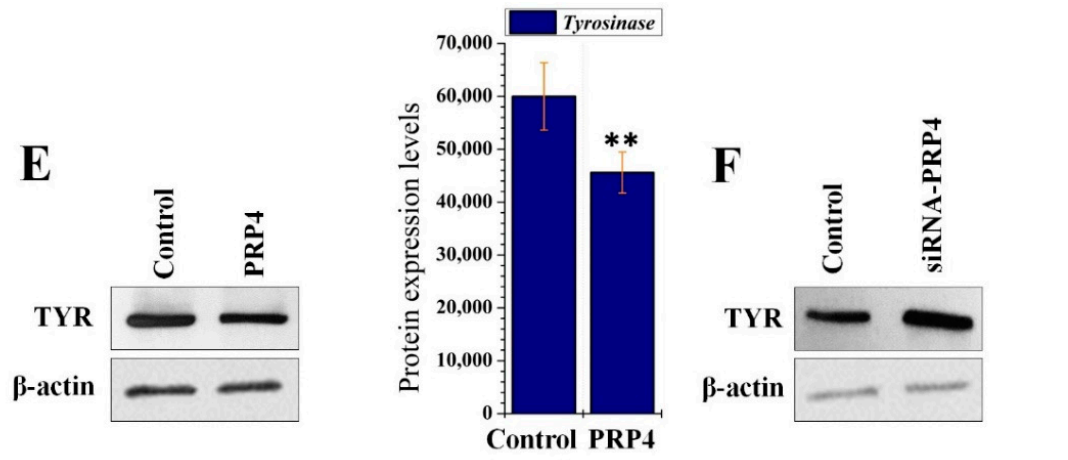

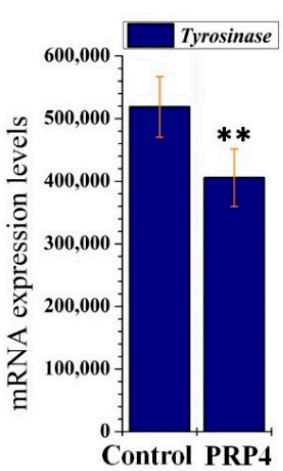

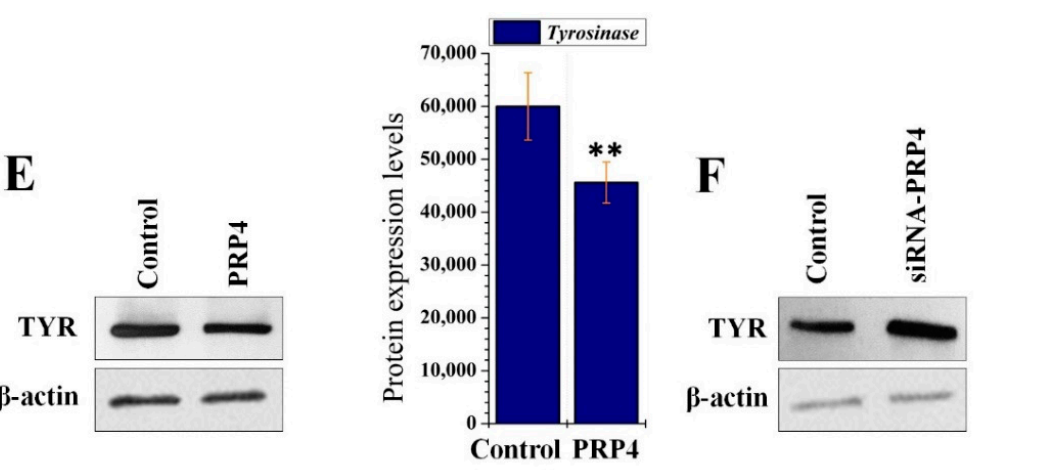

B

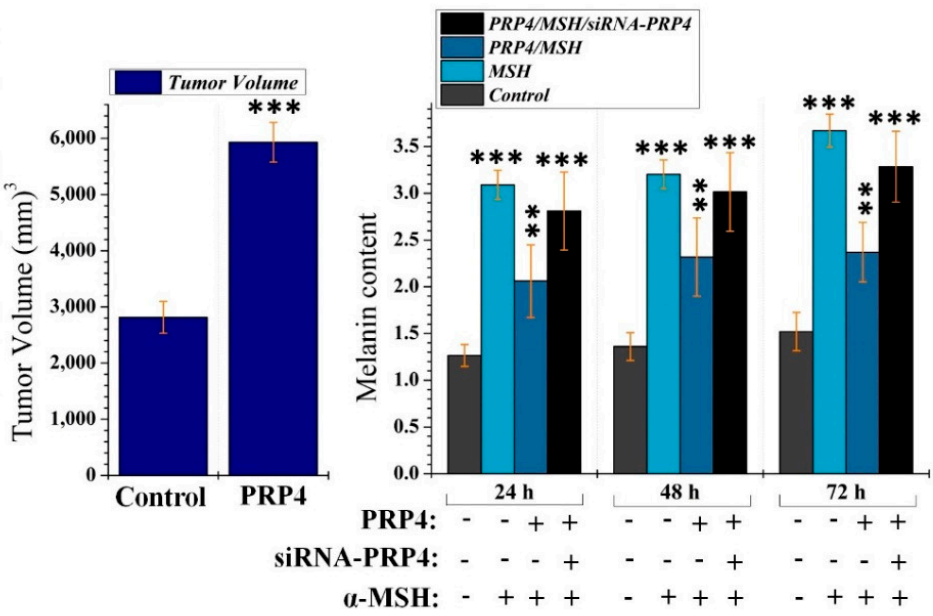

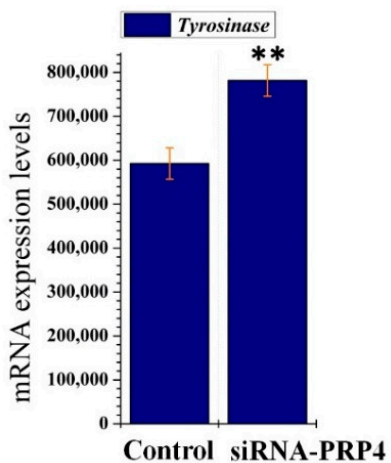

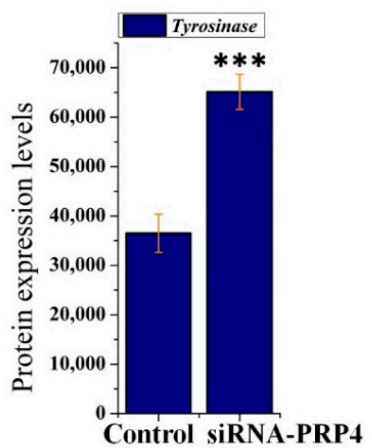

Figure 1. PRP4 inhibits the production of melanin in B16F10 cells, which subsequently leads to the promotion of skin cancer. (A) Nude mice $(n=6)$ received parental and PRP4-transfected B16F10 cells into the left and right flank, respectively, by subcutaneous injection. Data were collected from 3 independent experiments. ${ }^{* * *} p<0.001$. For clear visibility of the tumors in vivo, the same mouse was photographed twice; the tumors are encircled in the latter set of photographs. (B) Melanin production in PRP4 transfected B16F10 melanoma cells. The cells were transfected with $5 \mu \mathrm{g}$ PRP4 for 24, 48, and 72 h, and $\alpha$-MSH was used as a positive control. Data were collected from 3 independent experiments. ${ }^{* *} p<0.01,{ }^{* *} p<0.001$. (C,D) Triplicate total RNA samples from control and the PRP4 and siRNA-PRP4 transfected cells were analyzed by RT-PCR. ${ }^{* *} p<0.01$. (E,F) Solubilized proteins $(20 \mu \mathrm{g})$ from PRP4 and siRNA-PRP4 transfected cultured cells were subjected to Western blot analysis using the corresponding antibodies for detection of respective TYR protein. The blot was simultaneously incubated with an antiproteins antibody to show that each electrophoretic lane was loaded with the same amount of protein. $\beta$-actin was used as a standard. Data are presented as mean \pm standard deviation (SD) of at least three independent experiments $(n=3){ }^{* *} p<0.01,{ }^{* * *} p<0.001$. Treatment or transfection related abbreviations: PRP4 $=$ PRP4 cDNA plasmid transfection; siRNA-PRP4 = transfection of siRNA-PRP4; $\alpha-\mathrm{MSH}=100 \mathrm{~nm}$ treatment of $\alpha-\mathrm{MSH}$; TYR = tyrosine. 

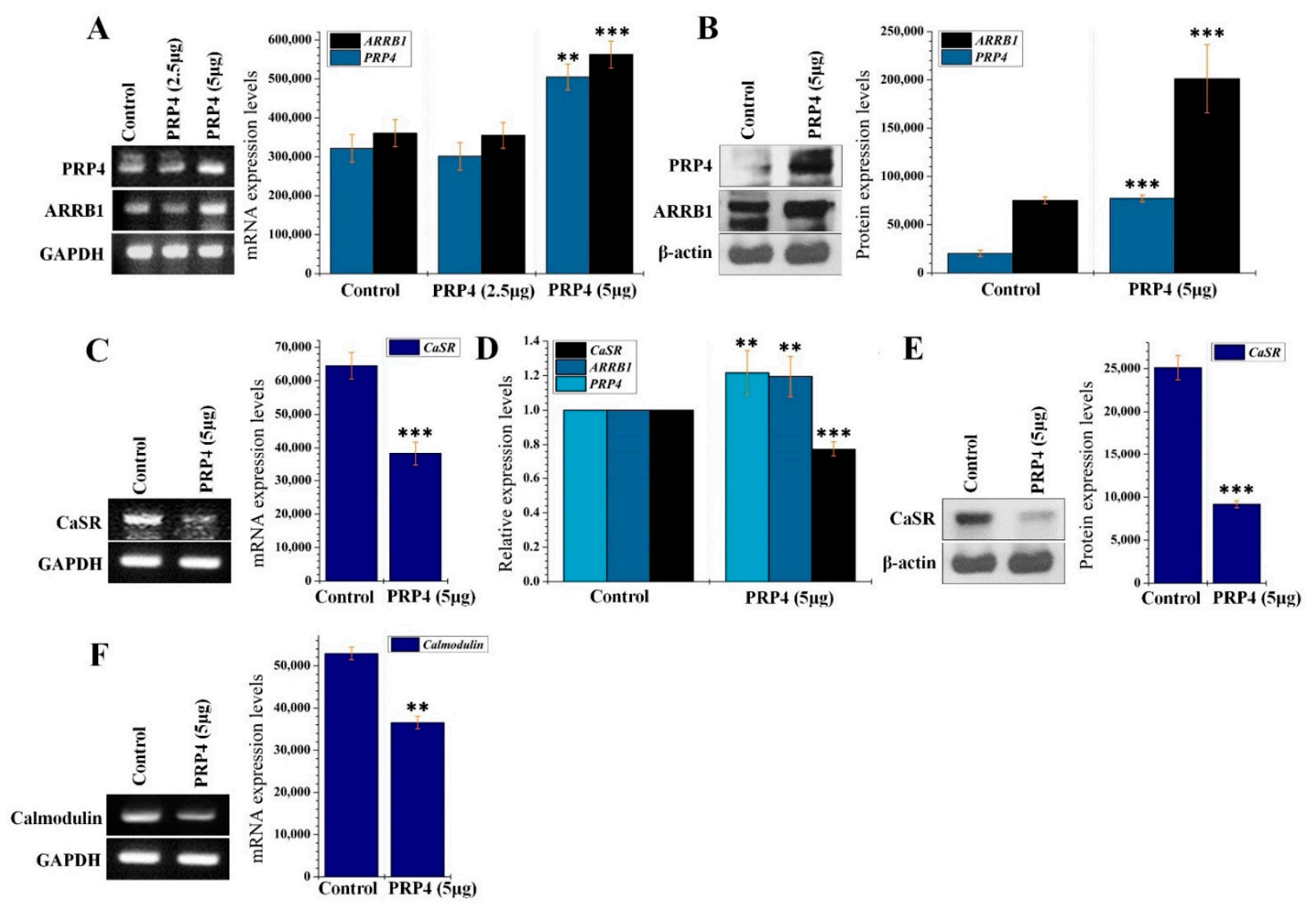

Figure 2. PRP4 regulates ARRB1-CaSR pathway. (A) Triplicate total RNA samples from control and the PRP4-transfected were analyzed by RT-PCR. ${ }^{* *} p<0.001$. (B) Solubilized proteins $(20 \mu \mathrm{g})$ from PRP4 transfected growing cells were subjected to Western blot analysis using the corresponding antibodies for detection of respective proteins. The blot was simultaneously incubated with an antiproteins antibody to show that each electrophoretic lane was loaded with the same amount of protein. $\beta$-actin was used as a standard. ${ }^{* *} p<0.001$. (C) Triplicate total RNA samples from control and the PRP4-transfected were analyzed for CaSR by RT-PCR. ${ }^{* * *} p<0.001$. (D) Gene expressions were quantified by using quantitative Real-Time PCR (qPCR). ${ }^{* *} p<0.01,{ }^{* * *} p<0.001$. (E) Solubilized proteins $(20 \mu \mathrm{g})$ from PRP4 transfected growing cells were subjected to Western blot analysis using the corresponding antibodies for detection of respective proteins. The blot was simultaneously incubated with an anti-proteins antibody to show that each electrophoretic lane was loaded with the same amount of protein. $\beta$-actin was used as a standard. ${ }^{* * *} p<0.001$. (F) Triplicate total RNA samples from control and the PRP4-transfected were analyzed for calmodulin by RT-PCR. GAPDH and $\beta$-actin were used as a standard. Data shown are mean with $95 \%$ confidence intervals of three qPCR assays. Data are presented as mean \pm standard deviation (SD) of at least three independent experiments. ${ }^{* *} p<0.01$.

To confirm that ARRB1 is upregulated by PRP4 overexpression, we performed PRP4's siRNA-mediated knockdown using a pool of three target-specific 19-25 nucleotide-long siRNAs (siRNA-PRP4). The siRNA-PRP4 inhibited both the PRP4 and the PRP4-induced expression of ARRB1 (Figure 3A). We further confirmed these results through Western blot and qPCR (Figure 3B,C). Additionally, we optimized the conditions for siRNA-ARRB1 transfection, where $30 \mathrm{nM}$ concentration significantly blocked the expression of ARRB1 (Figure 3D). Furthermore, siRNA-ARRB1 transfection activated the expression of CaSR and calmodulin, which indicates that these genes are the targets of ARRB1 (Figure 3E). Collectively, these findings indicate that PRP4 overexpression activates the expression ARRB1, which, in turn, induces the desensitization of CaSR and subsequently suppresses the expression of calmodulin. 

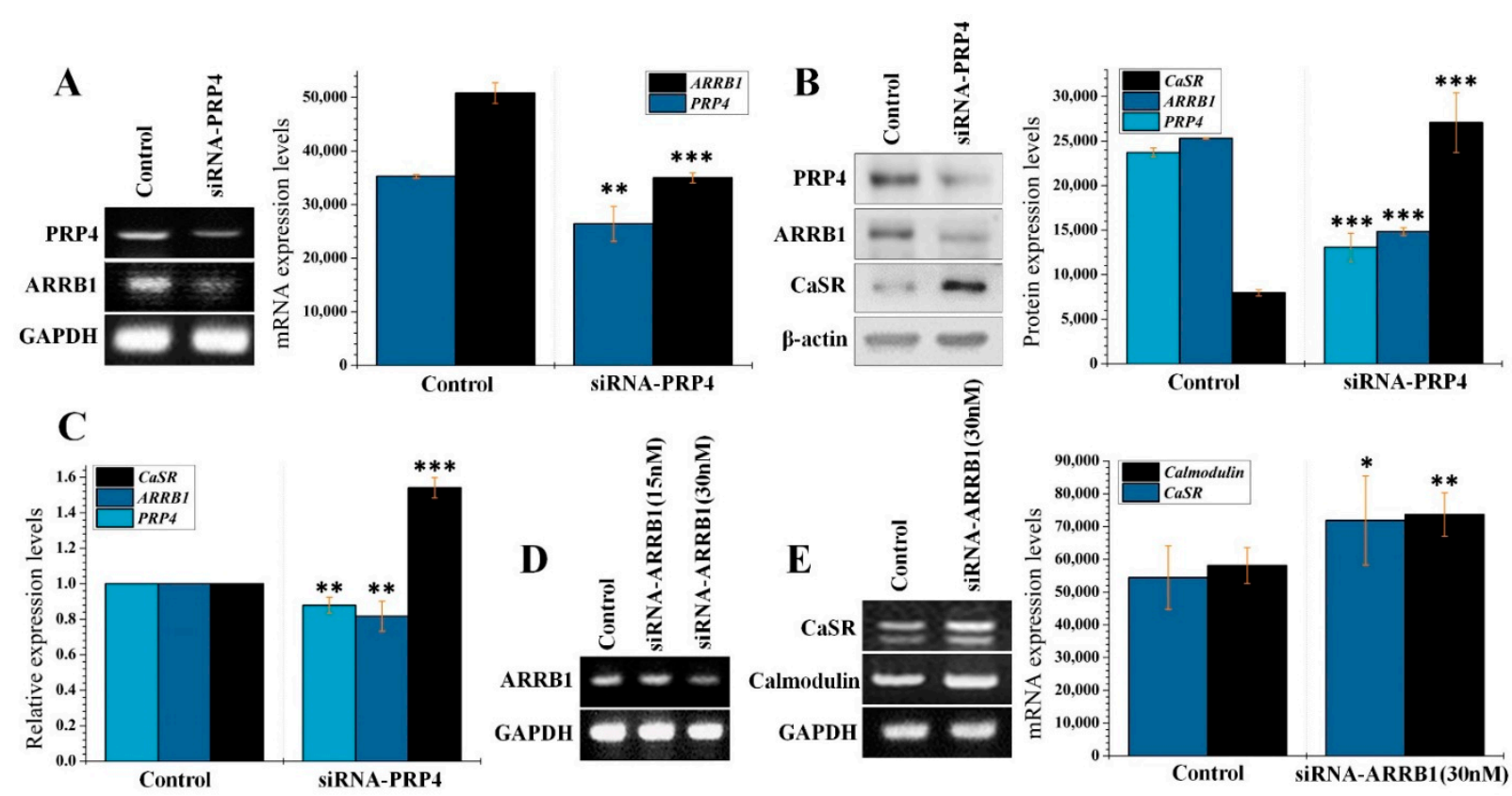

Figure 3. Interaction between PRP4 with the ARRB1-CaSR pathway. (A) Gene expression was assessed using siRNA-PRP4. Cells were assayed in triplicate from autonomous batches of RNA and sequestered from frozen pellets of cells grown under the same conditions on different days. The data shown are the mean and 95\% confidence intervals of three RT and qPCR assays. GAPDH was used as the standard control. ${ }^{* *} p<0.01,{ }^{* * *} p<0.001$. (B) Solubilized proteins (20 $\left.\mu \mathrm{g}\right)$ from siRNA-PRP4-transfected cultured cells were subjected to Western blot analysis using the corresponding antibodies for detection of respective proteins. The blot was simultaneously incubated with an antiproteins antibody to show that each electrophoretic lane was loaded with the same amount of protein. ${ }^{* *} p<0.001$. (C) Gene expressions were quantified using quantitative Real-Time PCR (qPCR) in siRNA-PRP4 transfected cells. ${ }^{* *} p<0.01,{ }^{* * *} p<0.001$. (D,E) Triplicate total RNA samples from control and the siRNA-ARRB1 transfected cells were analyzed by RT-PCR. GAPDH was used as a standard. Data are presented as mean \pm standard deviation (SD) of at least three independent experiments. ${ }^{*} p<0.05,{ }^{* *} p<0.01$. Treatment or transfection related abbreviations: siRNA-ARRB1 = transfection of siRNA-ARRB1.

\subsection{PRP4 Overexpression Reduces the Influx of $\mathrm{Ca}^{2+}$ and Downregulates Calmodulin}

We hypothesized that the influx of $\mathrm{Ca}^{2+}$ may be blocked through PRP4 and ARRB1mediated desensitization of CaSR. Therefore, we cultured B16F10 cells in $\mathrm{Ca}^{2+}$-rich media (supplemented with $1 \mathrm{mM}$ calcium) followed by transfection with either PRP4, ARRB1, siRNA-PRP4, or siRNA-ARRB1. Intracellular $\mathrm{Ca}^{2+}$ levels were evaluated and were reduced by PRP4 overexpression, whereas siRNA-mediated inhibition of PRP4 restored the intracellular concentration of $\mathrm{Ca}^{2+}$. Consistent results were obtained with ARRB1 and si-ARRB1 transfection (Figure 4A). To confirm our hypothesis that PRP4-induced inhibition of intracellular $\mathrm{Ca}^{2+}$ would downregulate the protein expression of calmodulin, we conducted Western blot, which demonstrated that PRP4 overexpression decreased the expression of calmodulin (Figure 4B). Furthermore, siRNA-PRP4 transfection restored calmodulin protein expression (Figure 4C). These results indicated that PRP4 overexpression may inhibit the influx of $\mathrm{Ca}^{2+}$ and downregulate the calmodulin through enhancing the ARRB1-mediated desensitization of CaSR.

\subsection{PRP4-Regulated CaSR-Induced $\mathrm{Ca}^{2+}$ Influx Occurs through the TRPC1 Channel in B16F10 Cells}

To investigate which channels were involved in the CaSR-induced $\mathrm{Ca}^{2+}$ influx in B16F10 cells, we analyzed the gene expressions of various ion channels including TRPC1/2/3/4 and 6. Of interest, TRPC1 was expressed in the B16F10 cells and was downregulated with siRNA-TRPC1 treatment (Figure 5A). We also observed mRNA expression of TRPC6; however, these levels were very low and negligible (data are not shown). 
To confirm the correlation of CaSR-induced $\mathrm{Ca}^{2+}$ with TRPC1, we conducted two separate experiments. First, B16F10 cells were transfected with si-RNA-PRP4, which resulted in the inhibition of ARRB1-mediated desensitization of CaSR and increased the influx of $\mathrm{Ca}^{2+}$ (as previously shown in Figure 4A). Then, B16F10 cells were transfected with siRNA-TRPC1, which dramatically reduced the influx of $\mathrm{Ca}^{2+}$ (Figure 5B), although PRP4 was blocked and CaSR was activated. These findings suggest that PRP4-regulated CaSR-induced $\mathrm{Ca}^{2+}$ influx occurs through the TRPC1 channel.

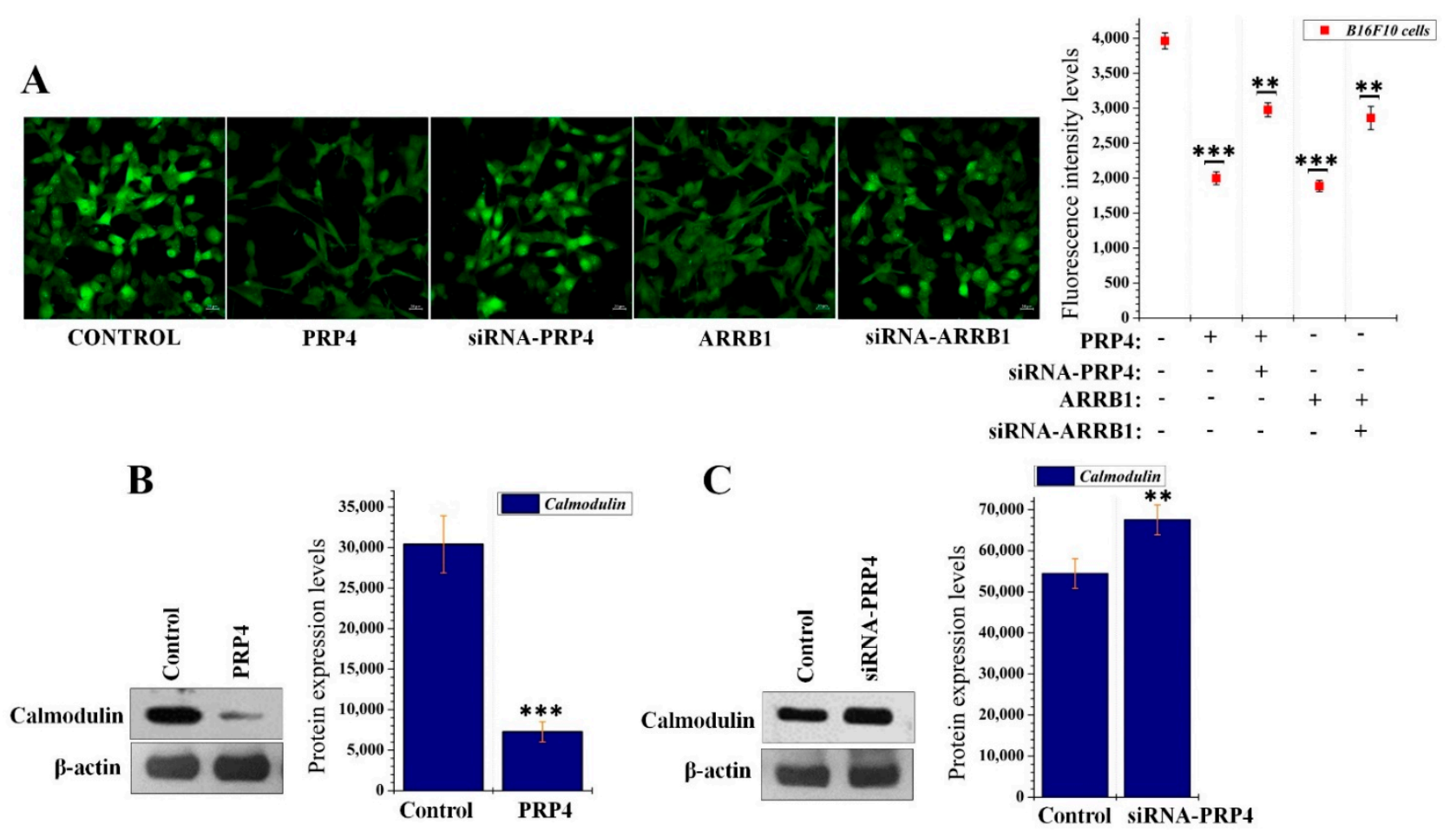

Figure 4. PRP4 reduces the influx of $\mathrm{Ca}^{2+}$ and decreases the expression of calmodulin. (A) PRP4, quadrant 4. ARRB1, or siRNA-ARRB1-transfected B16F10 cells were stained with Cal-520 AM to observe the intracellular calcium ions levels through fluorescence intensity levels. ${ }^{* *} p<0.01,{ }^{* * *} p<0.001$. (B,C) PRP4 and siRNA-PRP4-transfected B16F10 cells were analyzed with Western blotting to observe calmodulin (CALM1) expression. Data are presented as mean \pm standard deviation (SD) of at least three independent experiments. ${ }^{* *} p<0.01,{ }^{* *} p<0.001$. Treatment or transfection related abbreviations: ARRB1= transfection of ARRB1 plasmid.

\subsection{PRP4 Changes the Morphology of B16F10 by Regulating the AC-cAMP-RhoA Pathway}

$\mathrm{Ca}^{2+}$ either directly or indirectly (via calmodulin) regulates cAMP synthesis [48]. In connection with the effect of PRP4 overexpression upon intracellular $\mathrm{Ca}^{2+}$, to analyze the regulatory effect of PRP4 on AC and cAMP was of interest in this study. B16F10 were transfected with PRP4 overexpression plasmid and total cell lysates were analyzed by Western blot. It was observed that PRP4 overexpression significantly downregulated the expression of AC, whereas inhibition of PRP4 through siRNA restored the expression of AC (Figure 6A). Next, we analyzed the effect of PRP4 overexpression on the synthesis of cAMP. In line with the inhibition of AC by PRP4 overexpression, cAMP synthesis was also blocked by PRP4 and subsequently restored after siRNA-mediated knockdown of PRP4 (Figure 6B). Multiple previous studies have shown that cAMP regulates RhoA and leads to morphological changes in the cells [49]. Previously, we have reported that PRP4 overexpression induced actin filament redistribution and modified cell morphology from an aggregated, flattened shape to a round shape through inhibition of RhoA activity. To evaluate whether the regulatory effect of PRP4 upon AC and cAMP affected RhoA, we conducted Western blot analysis using the same cell lysates as used in Figure 6A. We observed that PRP4 downregulated the activity of RhoA, and the action of PRP4 was 
reversed after the utilization of siRNA-PRP4 (Figure 6C). Due to the PRP4 regulatory action on RhoA, we analyzed the actin cytoskeleton of B16F10 cells. This data demonstrated that PRP4 effectively regulated the actin cytoskeleton and morphology of the B16F10 cells, while not affecting the nuclei of the cells (Figure 6D). These findings suggest that PRP4 remodels the morphology of B16F10 by regulating the AC-cAMP-RhoA pathway.
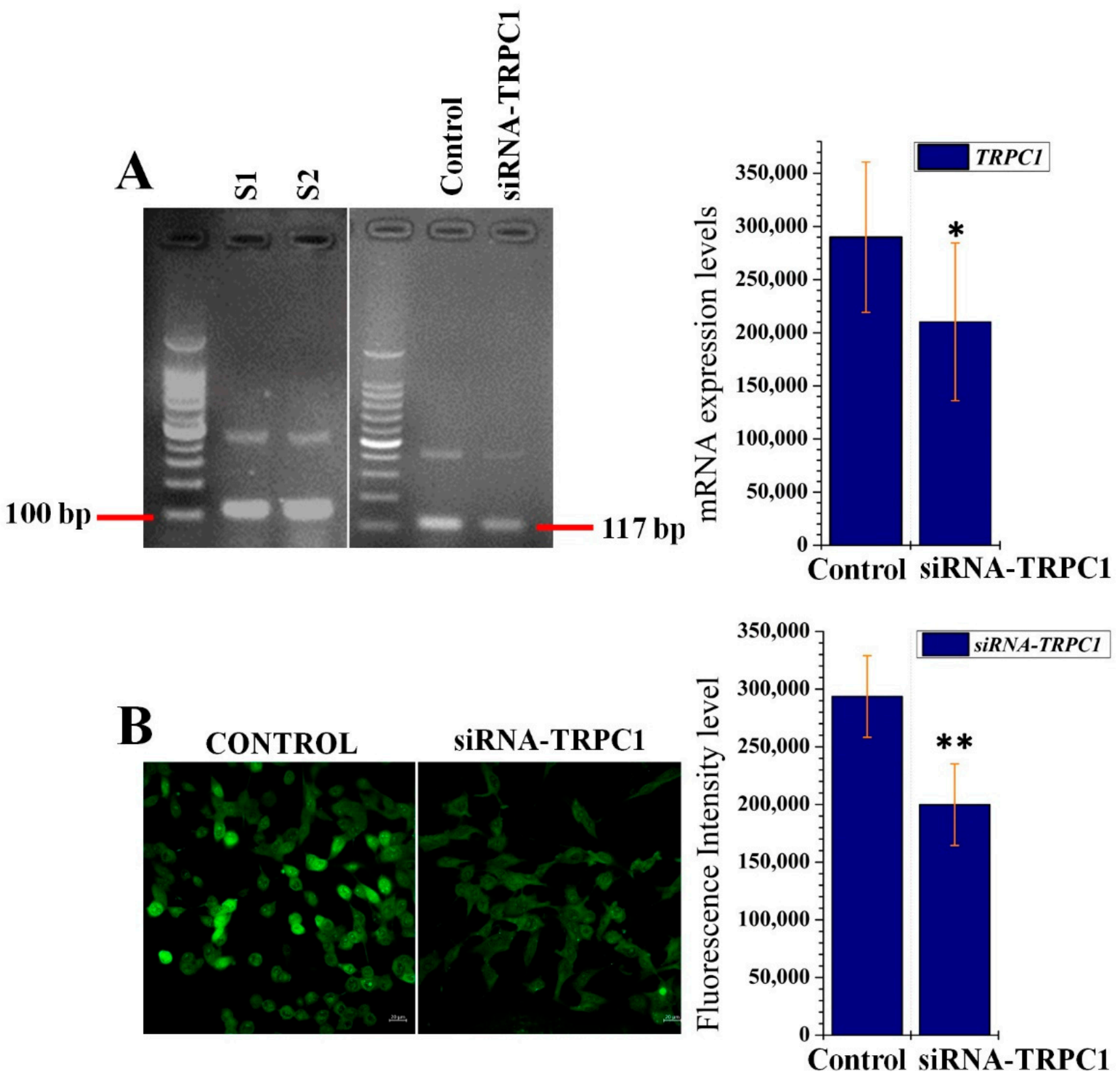

Figure 5. PRP4-regulated CaSR-induced $\mathrm{Ca}^{2+}$ influx occurs through the TRPC1 channel in B16F10 cells. (A) Triplicate total RNA samples from control and the siRNA-transient receptor potential canonical 1 (TRPC1) transfected cell were analyzed by RT-PCR. GAPDH was used as the standard control. ${ }^{*} p<0.05$. (B) siRNA-TRPC1-transfected B16F10 cells were stained with Cal-520 AM to observe the intracellular calcium ions levels through fluorescence intensity levels. Data are presented as mean \pm standard deviation (SD) of at least three independent experiments. ${ }^{* *} p<0.01$. Treatment or transfection related abbreviations: S1 = sample 1; S2 = sample 2; siRNA-TRPC1 = transfection of siRNA-TRPC1. 

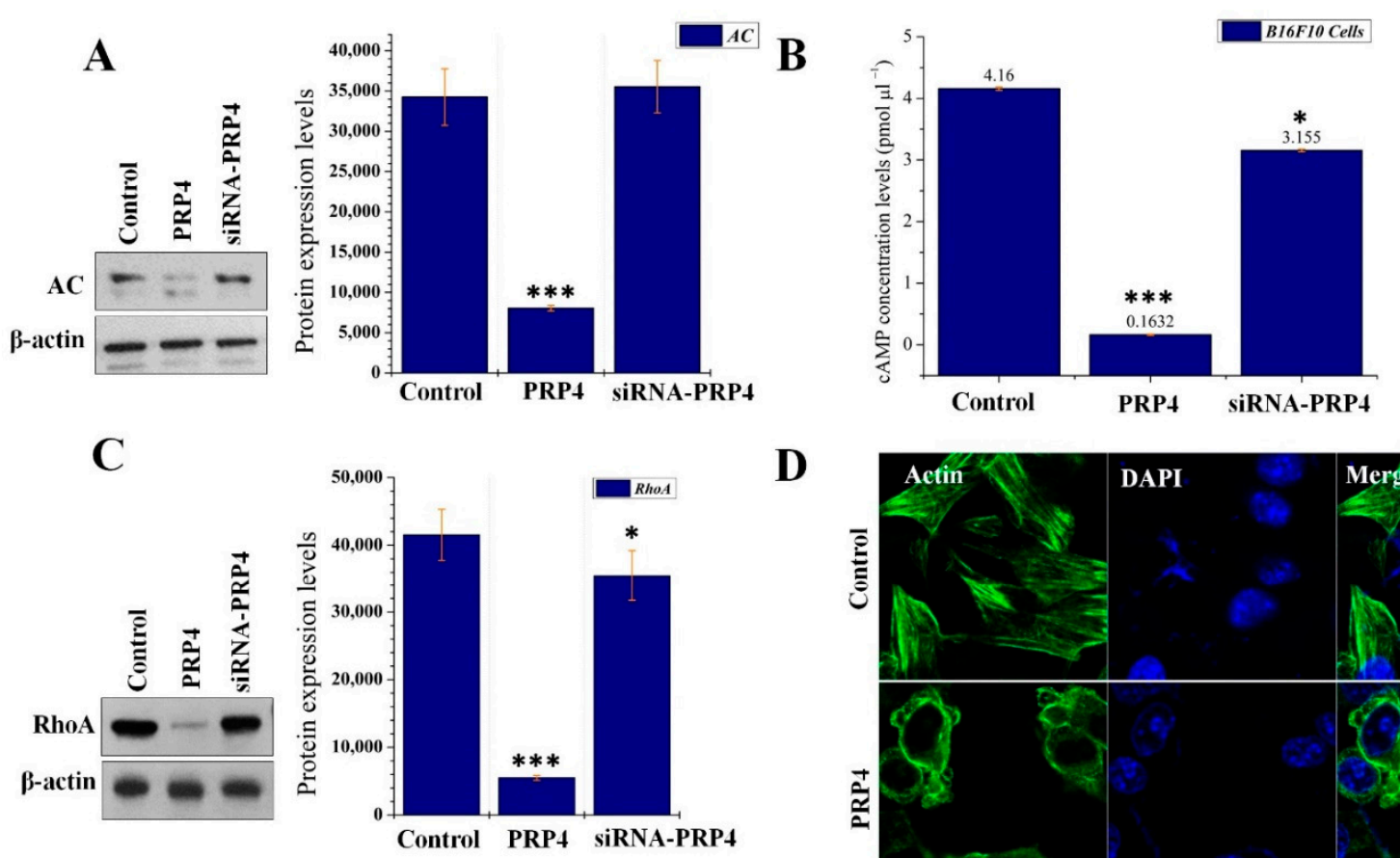

D

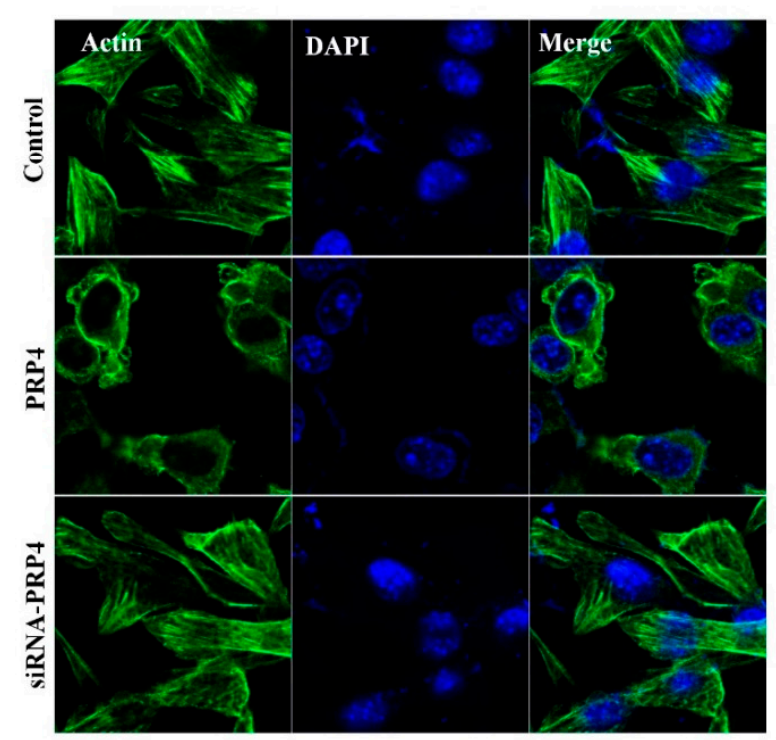

Figure 6. PRP4 alters the morphology of B16F10 cells. (A,C) Solubilized proteins (20 $\mu \mathrm{g})$ from PRP4 and siRNA-PRP4transfected cultured cells were subjected to Western blot analysis using the corresponding antibodies for detection of respective adenylyl cyclase and RhoA proteins. The blot was simultaneously incubated with an anti-proteins antibody to show that each electrophoretic lane was loaded with the same amount of protein. $\beta$-actin was used as a standard. ${ }^{*} p<0.05,{ }^{* * *} p<0.001$. (B) Corresponding cells were observed for cAMP levels using a cAMP assay kit, and plated cells were measured in a microplate reader (OD $450 \mathrm{~nm}$ ). ${ }^{*} p<0.05,{ }^{* * *} p<0.001$. (D) PRP4 and siRNA-PRP4 transfected B16F10 cells were stained with Alexa Fluor ${ }^{\mathrm{TM}} 488$ Phalloidin to observe the structure of actin stress fiber formation. Nuclei were counterstained with DAPI, and cells were imaged using a confocal microscope (Carl Zeiss).

\section{Discussion}

B16F10 cells have been extensively used for studies of melanogenesis and depigmentation [50]. In this study, we were interested to analyze the impact PRP4 has upon melanin production. B16F10 cells were treated with $\alpha$-MSH followed by PRP4/siRNA-PRP4 transfection. The results demonstrated that PRP4 overexpression blocked the $\alpha$-MSH-induced melanin production in B16F10 cells. Upon further confirmation, we found that mRNA and protein levels of tyrosine were consistently downregulated by PRP4 overexpression. We suggest that PRP4 decreased the production of melanin in B16F10 cells by downregulating AC-cAMP-MITF-tyrosine signaling pathway, which may promote skin carcinogenesis and drug resistance.

Other supportive mechanisms of PRP4 in promoting skin carcinogenesis and induction of drug resistance were evaluated in this study. PRP4 upregulated the expression of ARRB1, which in turn desensitized CaSR. Upon desensitization, CaSR inhibited the influx of $\mathrm{Ca}^{2+}$, which was evident from the observed decreased calmodulin expression. Our results are consistent with previous investigations, which report that $\mathrm{Ca}^{2+}$ is deregulated in cancer [51-54]. To confirm the link of PRP4 with ARRB1-CaSR-calmodulin, we 
utilized siRNA-PRP4, which silenced PRP4 and inhibited its effect upon ARRB1, CaSR, and calmodulin.

$\mathrm{Ca}^{2+}$ influx is induced by CaSR through store-operated channels, which, in many cases, have been identified as TRP family members [23]. We were interested in identifying the channel through which CaSR mediated the $\mathrm{Ca}^{2+}$ influx in B16F10 cells. For this purpose, we analyzed the gene expressions of various ion channels including TRPC $1 / 2 / 3 / 4$ and 6 in B16F10 cells. We noted that only TRPC1 mRNA expression was detectable, whereas TRPC6 presented very low mRNA expression levels. TRPC2/3 and 4 were not present in B16F10 cells. Furthermore, we transfected B16F10 cells with siRNA-PRP4, which resulted in the inhibition of ARRB1-mediated desensitization of CaSR and increased the influx of $\mathrm{Ca}^{2+}$. We subsequently transfected B16F10 cells with siRNA-TRPC1, which dramatically reduced the influx of $\mathrm{Ca}^{2+}$. Our findings suggest that PRP4 regulated CaSR-induced $\mathrm{Ca}^{2+}$ influx occurs through the opening of the TRPC1 channel.

Previously, we have shown that PRP4 induced changes to the cell cytoskeletal architecture and thereby induced EMT. Although PRP4 has been shown to alter cell cytoskeletal architecture in multiple cell lines, we have demonstrated these findings in B16F10 cell lines [44]; where it was observed that PRP4 transfection significantly decreased the expression of AC. We also analyzed the effect of PRP4 overexpression on the synthesis of cAMP. In line with the inhibition of AC by PRP4 overexpression, cAMP synthesis was also inhibited by PRP4. We further analyzed whether PRP4 is involved in the cAMP regulatory action on cell morphology [49]. Through Western blot, we observed that PRP4 downregulated the activity of RhoA, and effectively remodeled the actin cytoskeleton and morphology of the B16F10 cells. These findings indicate that PRP4 remodels the morphology of B16F10 cells by regulating the AC-cAMP-RhoA pathway. These results also serve as an extension to our previous study in which it was reported that PRP4 overexpression inhibited the RhoROCKLIMK-cofilin pathway and ultimately induced cofilin dephosphorylation, which resulted in F-actin stabilization and redistribution of cytoplasmic actin [45].

\section{Materials and Methods}

\subsection{Chemicals and Reagents}

Cell lines were purchased from the American Type Culture Collection (Manassas, VA, USA). Dulbecco's modified Eagle's medium (DMEM), fetal bovine serum (FBS), and penicillin/streptomycin were obtained from Gibco (Carlsbad, CA, USA). We purchased the PRP4 cDNA clone (Cat\# HG10835-M) and ARRB1 cDNA clone (Cat\# HG12310-CF) from Sino Biological (North Wales, PA, USA). siRNA-ARRB1 (sc-29741), siRNA-PRP4 (sc-76257), and siRNA-TRPC1 (SC-42664) were purchased from Santa Cruz. Lipofectamine RNAiMAX Transfection Reagent was purchased from Invitrogen. Xfect transfection reagent was purchased from Takara Bio USA, Inc. (Mountain View, CA, USA). Cal-520 AM assay kit (ab171868), $1 \mathrm{mM} \mathrm{Ca}^{2+}$ supplemented buffer, and cAMP assay kit (ab65355) were obtained from Abcam. Bradford protein assay kit and electrophoresis reagents were purchased from Bio-Rad Laboratories (Irvine, CA, USA). Antibodies were obtained from Santa Cruz Biotech [PRP4 (sc-130856), $\beta$-actin (sc-47778), ARRB1 (sc-53780), Tyrosinase (sc-20035), CaSR (sc47741), adenylyl cyclase (sc-365350)] and cell signaling technology [calmodulin (cat \#4830), RhoA (cat \# 2117), anti-mouse IgG-HRP-linked (cat \#7076), and anti-rabbit IgG-HRP-linked (cat \#7074)]. ECL Prime detection reagent and nitrocellulose membrane were purchased from Amersham (Little Chalfont, Buckinghamshire, UK). Vectashield mounting medium with DAPI (4',6-diamidino-2-phenylindole) from Vector Laboratories Inc. (Burlingame, CA, USA) was used for nuclei staining. SuperScript III Reverse Transcriptase (Cat \#18080093) was obtained from Invitrogen (Carlsbad, CA, USA). Actin-stain ${ }^{\mathrm{TM}} 488$ Phalloidin (A12379) was obtained from ThermoFisher scientific, and $\alpha-\mathrm{MSH}$ (M4135) was purchased from Sigma Aldrich. All chemicals and reagents were used according to the manufacturer's instructions. 


\subsection{Cell Culture and Double Transient Transfections}

B16F10 (ATCC CRL-6475) cells were cultured in DMEM containing $1 \mathrm{mM} \mathrm{Ca}^{2+}$, supplemented with $10 \% \mathrm{FBS}$ and $2 \%$ penicillin-streptomycin, and were maintained at $37{ }^{\circ} \mathrm{C}$ in a humidified atmosphere containing $5 \% \mathrm{CO}_{2}$.

\subsection{Plasmid Transfection and Gene Knock Down by siRNA}

PRP4 overexpression was achieved by transfecting cells with PRP4 expression plasmids. Briefly, B16F10 cells were cultured at a density of $1 \times 10^{6}$ cells to $50 \%$ confluence. Then, the PRP4 plasmid was transfected into the cells using the Xfect Transfection Reagent, whereas siRNA-PRP4 was transfected with RNAiMAX, according to the manufacturer's instructions. Similarly, siRNA-ARRB1 and siRNA-TRPC1 were also transfected with RNAiMAX. Gene overexpression and downregulation were confirmed by agarose gel electrophoresis and SDS-PAGE.

\subsection{Reverse Transcription-Polymerase Chain Reaction (RT-PCR)}

For cDNA synthesis, total RNA $(5 \mu \mathrm{g})$ was reverse transcribed using the SuperScript III First-strand synthesis kit as previously described [23]. The synthesized cDNA was incubated with RNase $\mathrm{H}$ at $37^{\circ} \mathrm{C}$ for $2 \mathrm{~h}$. PCR was performed using $2 \mu \mathrm{L}$ of cDNA and primers used were PRP4 forward, $5^{\prime}$-AGGGATCGAAGCTGGAAATA- $3^{\prime}$ and PRP4 reverse, $5^{\prime}$-TGACCTCTGAGTCATCT-GTGG-3'; CaSR forward, 5'-CTGAAGAGAAGGCAACGCT ATG-3' ${ }^{\prime}$ and CaSR reverse, $5^{\prime}$ - GGGCAACAAAACTCAAGGT $-3^{\prime}$; ARRB1 forward, $5^{\prime}-$ CGGATGCTTTCTCGTCTC- $3^{\prime}$ and ARRB1 reverse, 5'-ACCCATCATCATTGTGCC-3'; calmodulin forward $5^{\prime}$-CCCTCTGTCCACACACAAAG-3' and calmodulin reverse, $5^{\prime}$ TTGATGGTGTGCTCAAGTCC-3' ${ }^{\prime}$ TRPC1 forward 5'-CCTCCTTGTTCTGTTTTCCTTC-3'; and TRPC 1 reverse $5^{\prime}$-GTGTCATTGCTTTGCTGTTC-3'; TYR forward $5^{\prime}$ - GCTGCAGGAG CCTTCTTTCTC-3'; and TYR reverse $5^{\prime}$-AAGACGCTGCACTGCTGGTCT-3'; ; glyceraldeh yde-3-phosphate dehydrogenase (GAPDH) forward, 5'-AGGGCTGCTTTTAACTCTGGT-3' and GAPDH reverse, $5^{\prime}$-CCCCACTTGATTTTGGAGGGA-3'. PCR cycles were run as follows: one cycle at $98{ }^{\circ} \mathrm{C}$ for $3 \mathrm{~min}$, followed by $30-35$ cycles at $95{ }^{\circ} \mathrm{C}$ for $30 \mathrm{~s}, 5{ }^{\circ} \mathrm{C}$ for $30 \mathrm{~s}$, and $72{ }^{\circ} \mathrm{C}$ for $30 \mathrm{~s}$, with a final extension step at $72{ }^{\circ} \mathrm{C}$ for $5 \mathrm{~min}$. The amplified PCR products were analyzed by $2 \%$ agarose gel electrophoresis and EcoDye Nucleic Acid Staining Solution (Biofact). Images were subsequently captured using Wise Capture I-1000 software (Daihan Scientific, Seoul, Korea).

\subsection{Relative qRT-PCR Analysis}

Trizol reagent was used to extract total RNA (Life Technologies, Grand Island, NY, USA) according to the manufacturer's instructions. qRT-PCR was performed in NanoQ (OPTIZEN, Daejeon, Korea) with reagents obtained from TaKaRa Biotechnology Co., Ltd. (Dalian, China). DNA (cDNA) was synthesized as per manufacturer protocol SuperScript ${ }^{\circledR}$ VILO $^{\mathrm{TM}}$ cDNA synthesis kit (Life Technologies). PCR cycles were performed with specific primers using a two-step reaction and run using the Eco TM Real-Time PCR system (Illumina, CA, USA). The master mix consisted of $2 \times$ Real-Time PCR Master mix containing SYBR Green I (BIOFACT, Korea) with $100 \mathrm{ng}$ of template DNA and $10 \mathrm{nM}$ of each primer in a final volume of $20 \mu \mathrm{L}$. The qPCR cycle was run at $95^{\circ} \mathrm{C}$ for $15 \mathrm{~min}$, with concurrent denaturation at $95^{\circ} \mathrm{C}$, annealing and extension at $60^{\circ} \mathrm{C}$ for $34 \mathrm{~s}$ for 40 cycles. Primers for PRP4, ARRB1, CaSR, and GAPDH were the same as those described for RT-PCR.

\subsection{F-Actin Staining}

Alexa Fluor 488 phalloidin was used for F-actin visualization. Briefly, after removal of the growth medium, cells were washed twice with PBS and fixed with $4 \%$ paraformaldehyde for $15 \mathrm{~min}$ at room temperature. Cells were permeabilized with $0.2 \%$ Triton X-100 for $5 \mathrm{~min}$ and washed 2-3 times with PBS. The Alexa Fluor 488 phalloidin stock solution (6.6 $\mu \mathrm{M}$ in methanol) was diluted 1:40 with $1 \%$ bovine serum albumin and added to the cells for $50 \mathrm{~min}$ at room temperature in the dark. Cells were further washed with PBS 
5-6 times and actin cytoskeleton were observed using a ZEISS LSM 800 confocal microscope at $1000 \times$ magnification.

\subsection{Cal-520 AM Assay}

B16F10 cells were cultured in DMEM containing $1 \mathrm{mM} \mathrm{Ca}^{2+}$ supplemented with $10 \%$ fetal bovine serum (Hy Clone, USA) in $5 \% \mathrm{CO}_{2}$ at $37^{\circ} \mathrm{C}$. Cells were transfected with respective siRNAs and incubated for $6 \mathrm{~h}$ in serum-free optimum medium. At $7 \mathrm{~h}$, full serum DMEM media was added to the cells and incubated for a following $17 \mathrm{~h}$. Cells were subsequently loaded with Cal-520 AM dye $(10 \mathrm{mM})$ in $200 \mu \mathrm{L}$ HHBS buffer with Pluronic F-127 (0.01\%) for $30 \mathrm{~min}$ at $37^{\circ} \mathrm{C}$. This indicator has high-affinity binding to $\mathrm{Ca}^{2+}\left(\mathrm{K}_{\mathrm{d}}=\frac{1}{4}\right.$ $345 \mathrm{nM}$ ) and will indicate a significant increase in fluorescence intensity in response to $\mathrm{Ca}^{2+}$ binding ( $>100$ fold). Cells were washed twice with HHBS Solution, and images of calcium-dependent fluorescence were obtained using a FITC- ZEISS LSM 800 confocal microscope $492 \mathrm{~nm}$.

\section{8. cAMP Assay}

B16F10 cells were cultured and transfected with PRP4, then collected and lysed, and the levels of cAMP intracellularly were assessed using a cAMP assay kit according to the manufacturer's protocol. The assay was repeated in triplicate.

\subsection{Animal Study Protocol}

We housed 6 male BALB/c-n mice at a density of two mice per cage, under conditions of constant temperature $\left(22^{\circ} \mathrm{C}\right)$ and a light/dark cycle of $12 \mathrm{~h}$. Our experimental protocol complied with the animal maintenance and use guidelines of Kyungpook National University. We suspended a total of $10^{6}$ parental or PRP4-transfected B16F106 cells in $150 \mu \mathrm{L}$ PBS and implanted them subcutaneously into 6-week-old mice at specific left and right sites using an insulin syringe. We recorded tumor volumes weekly using a Vernier caliper and calculated them according to the formula: $\mathrm{V}=4 / 3 \pi \mathrm{W} 2 \mathrm{~L}$ (short diameter $2 \times$ long diameter [mm3]). We excised the tumors 30-45 days after cells' postimplantation using scissors.

\subsection{Measurement of Melanin Content}

B16F10 cells were seeded into a $60 \mathrm{~mm}$ dish and incubated for $24 \mathrm{~h}$. Next, media was replaced with serum-free optimum media, and the cells were transfected with PRP4, and incubated with $200 \mathrm{nM} \alpha-\mathrm{MSH}$ for $24-72 \mathrm{~h}$. After the incubation period, cells were washed with PBS and dissolved in $2 \mathrm{~mL} 1 \mathrm{~N} \mathrm{NaOH}$ containing $10 \% \mathrm{DMSO}$ at $70{ }^{\circ} \mathrm{C}$ for $1 \mathrm{~h}$. To this, $200 \mu \mathrm{L} \mathrm{NaOH}$ solution aliquots were added to the 96-well plate, and the absorbance was measured at $405 \mathrm{~nm}$ on a spectrophotometric microplate reader (Tecan, Mannedorf, Switzerland).

\subsection{Western Blot}

Cells were collected with a cell scrapper in PBS and centrifuged at 12,000 rpm for $5 \mathrm{~min}$ to obtain the cell pellet. The supernatant was discarded, and the cell pellet was resuspended in $200 \mu \mathrm{L}$ of cell lysis buffer [ $50 \mathrm{mM}$ Tris, $\mathrm{pH} 7.4,0.5 \%$ NP40, $0.01 \%$ SDS, and protease inhibitor cocktail (Roche, Germany)]. Total cells lysates were then quantified using the Bio-Rad Protein Assay according to the manufacturer's protocol. Samples $(20-40 \mu \mathrm{g})$ were prepared in SDS sample buffer containing $60 \mathrm{mM}$ Tris- $\mathrm{HCl}$ (pH 6.8), $2 \%$ SDS, $10 \%$ glycerol, and $5 \% \beta$-mercaptoethanol, and separated on a 10-12\% SDS-PAGE gel and transferred onto a polyvinylidene fluoride (PVDF) membrane (Amersham, Piscataway, NJ, USA). Membranes were blocked with 3\% albumin (Gendepot, USA) solution for $2 \mathrm{~h}$ at $4{ }^{\circ} \mathrm{C}$. Chemiluminescent signals were developed using a Clarity ECL Western Blotting Substrate (Bio-Rad) according to the manufacturer's instructions. 


\subsection{Statistical Analysis}

All samples and experiments were prepared and run-in triplicate. Data are presented as mean \pm standard deviation (SD). A Student t-test was used to evaluate differences between groups and $p$-values $<0.05$ were considered statistically significant.

\section{Conclusions}

Our study demonstrates that PRP4 inhibits the production of melanin in B16F10 cells, which may promote skin carcinogenesis and drug resistance. The two other supporting mechanisms for cancer promotion and drug resistance in B16F10 cells include PRP4induced inhibition of $\mathrm{Ca}^{2+}$ influx through CaSR desensitization and remodeling of the cell actin cytoskeleton by the downregulation of the AC-cAMP-RhoA signaling pathway (Graphical abstract).

Author Contributions: Y.S.L. conceived and designed the experiments. M.B.A. and S.U.I. performed the experiments and wrote the manuscript. All authors have read and agreed to the published version of the manuscript.

Funding: This research was supported by the National Research Foundation of Korea (NRF) grant funded by the Korean government (MSIT) (NRF-2019R1A2C1003003).

Institutional Review Board Statement: Our experimental protocol complied with the animal maintenance and use guidelines of Kyungpook National University (2012-37).

Informed Consent Statement: Not Applicable.

Data Availability Statement: The data that support the findings of this study are available on request from the corresponding author.

Acknowledgments: Not Applicable.

Conflicts of Interest: The authors have no potential conflict of interest to disclose.

$\begin{array}{ll}\text { Abbreviations } \\ \text { PRP4 } & \text { Pre-mRNA processing factor 4B } \\ \text { EMT } & \text { Epithelial-mesenchymal transition } \\ \text { AC } & \text { Adenylyl cyclase } \\ \text { CaSR } & \text { Calcium-sensing receptor } \\ \text { RhoA } & \text { Ras homolog family member A } \\ \text { TRP-1 } & \text { Tyrosinase-related protein } \\ \text { MITF } & \text { Microphthalmia-associated transcription factor } \\ \text { CREB } & \text { cAMP response element-binding protein } \\ \text { ERK } & \text { Extracellular-regulated kinase } \\ \alpha-M S H & \text { Alpha-melanocyte stimulating hormone } \\ \text { GPCR } & \text { G-protein-coupled receptor } \\ \text { GRKs } & \text { G protein-coupled receptor kinase } \\ \text { TRP } & \text { Transient receptor potential } \\ \text { TRPC1 } & \text { Transient receptor potential canonical 1 } \\ \text { cAMP } & \text { Cyclic adenosine } 3^{\prime}, 5^{\prime} \text {-monophosphate } \\ \text { MC1R } & \text { Melanocortin 1 receptor }\end{array}$

\section{References}

1. Martínez-Esparza, M.; Jiménez-Cervantes, C.; Beermann, F.; Aparicio, P.; Lozano, J.A.; García-Borrón, J.C. Transforming growth factor-beta1 inhibits basal melanogenesis in B16/F10 mouse melanoma cells by increasing the rate of degradation of tyrosinase and tyrosinase-related protein-1. J. Biol. Chem. 1997, 272, 3967-3972. [CrossRef] [PubMed]

2. Poste, G.; Doll, J.; Fidler, I.J. Interactions among clonal subpopulations affect stability of the metastatic phenotype in polyclonal populations of B16 melanoma cells. Proc. Natl. Acad. Sci. USA 1981, 78, 6226-6230. [CrossRef]

3. Calliste, C.A.; Trouillas, P.; Allais, D.P.; Simon, A.; Duroux, J.L. Free radical scavenging activities measured by electron spin resonance spectroscopy and B16 cell antiproliferative behaviors of seven plants. J. Agric. Food Chem. 2001, 49, 3321-3327. [CrossRef] 
4. Jin, K.S.; Oh, Y.N.; Hyun, S.K.; Kwon, H.J.; Kim, B.W. Betulinic acid isolated from Vitis amurensis root inhibits 3-isobutyl-1methylxanthine induced melanogenesis via the regulation of MEK/ERK and PI3K/Akt pathways in B16F10 cells. Food Chem. Toxicol. 2014, 68, 38-43. [CrossRef]

5. Bentley, N.J.; Eisen, T.; Goding, C.R. Melanocyte-specific expression of the human tyrosinase promoter: Activation by the microphthalmia gene product and role of the initiator. Mol. Cell. Biol. 1994, 14, 7996-8006. [CrossRef] [PubMed]

6. Bertolotto, C.; Buscà, R.; Abbe, P.; Bille, K.; Aberdam, E.; Ortonne, J.P.; Ballotti, R. Different cis-acting elements are involved in the regulation of TRP1 and TRP2 promoter activities by cyclic AMP: Pivotal role of M boxes (GTCATGTGCT) and of microphthalmia. Mol. Cell. Biol. 1998, 18, 694-702. [CrossRef] [PubMed]

7. Huang, H.C.; Chang, S.J.; Wu, C.Y.; Ke, H.J.; Chang, T.M. [6]-Shogaol inhibits $\alpha$-MSH-induced melanogenesis through the acceleration of ERK and PI3K/Akt-mediated MITF degradation. BioMed Res. Int. 2014, 2014, 842569. [CrossRef]

8. Gilchrest, B.A.; Eller, M.S.; Geller, A.C.; Yaar, M. The pathogenesis of melanoma induced by ultraviolet radiation. N. Engl. J. Med. 1999, 340, 1341-1348. [CrossRef] [PubMed]

9. Halder, R.M.; Bang, K.M. Skin cancer in blacks in the United States. Dermatol. Clin. 1988, 6, 397-405. [CrossRef]

10. Kaidbey, K.H.; Agin, P.P.; Sayre, R.M.; Kligman, A.M. Photoprotection by melanin-A comparison of black and Caucasian skin. J. Am. Acad. Dermatol. 1979, 1, 249-260. [CrossRef]

11. Szabó, G.; Gerald, A.B.; Pathak, M.A.; Fitzpatrick, T.B. Racial differences in the fate of melanosomes in human epidermis. Nature 1969, 222, 1081-1082. [CrossRef]

12. Kobayashi, N.; Nakagawa, A.; Muramatsu, T.; Yamashina, Y.; Shirai, T.; Hashimoto, M.W.; Ishigaki, Y.; Ohnishi, T.; Mori, T. Supranuclear melanin caps reduce ultraviolet induced DNA photoproducts in human epidermis. J. Investig. Dermatol. 1998, 110, 806-810. [CrossRef]

13. Vahe, C.; Benomar, K.; Espiard, S.; Coppin, L.; Jannin, A.; Odou, M.F.; Vantyghem, M.C. Diseases associated with calcium-sensing receptor. Orphanet J. Rare Dis. 2017, 12, 19. [CrossRef]

14. Thakker, R.V. Calcium-sensing receptor: Role in health and disease. Indian J. Endocrinol. Metab. 2012, 16 (Suppl. 2), S213-S216.

15. Lorenz, S.; Frenzel, R.; Paschke, R.; Breitwieser, G.E.; Miedlich, S.U. Functional desensitization of the extracellular calcium-sensing receptor is regulated via distinct mechanisms: Role of $\mathrm{G}$ protein-coupled receptor kinases, protein kinase $\mathrm{C}$ and beta-arrestins. Endocrinology 2007, 148, 2398-2404. [CrossRef]

16. Pi, M.; Oakley, R.H.; Gesty-Palmer, D.; Cruickshank, R.D.; Spurney, R.F.; Luttrell, L.M.; Quarles, L.D. Beta-arrestin- and G protein receptor kinase-mediated calcium-sensing receptor desensitization. Mol. Endocrinol. 2005, 19, 1078-1087. [CrossRef] [PubMed]

17. Reyes-Ibarra, A.P.; García-Regalado, A.; Ramírez-Rangel, I.; Esparza-Silva, A.L.; Valadez-Sánchez, M.; Vázquez-Prado, J.; Reyes-Cruz, G. Calcium-sensing receptor endocytosis links extracellular calcium signaling to parathyroid hormone-related peptide secretion via a Rab11a-dependent and AMSH-sensitive mechanism. Mol. Endocrinol. 2007, 21, 1394-1407. [CrossRef] [PubMed]

18. Nesbit, M.A.; Hannan, F.M.; Howles, S.A.; Reed, A.A.; Cranston, T.; Thakker, C.E.; Gregory, L.; Rimmer, A.J.; Rust, N.; Graham, U.; et al. Mutations in AP2S1 cause familial hypocalciuric hypercalcemia type 3. Nat. Genet. 2013, 45, 93-97. [CrossRef] [PubMed]

19. Zhuang, X.; Northup, J.K.; Ray, K. Large putative PEST-like sequence motif at the carboxyl tail of human calcium receptor directs lysosomal degradation and regulates cell surface receptor level. J. Biol. Chem. 2012, 287, 4165-4176. [CrossRef] [PubMed]

20. Hanyaloglu, A.C.; von Zastrow, M. Regulation of GPCRs by endocytic membrane trafficking and its potential implications. Annu. Rev. Pharmacol. Toxicol. 2008, 48, 537-568. [CrossRef]

21. Moore, C.A.; Milano, S.K.; Benovic, J.L. Regulation of receptor trafficking by GRKs and arrestins. Annu. Rev. Physiol. 2007, 69, 451-482. [CrossRef] [PubMed]

22. DeWire, S.M.; Ahn, S.; Lefkowitz, R.J.; Shenoy, S.K. Beta-arrestins and cell signaling. Annu. Rev. Physiol. 2007, 69, 483-510. [CrossRef]

23. Ambudkar, I.S.; Ong, H.L.; Liu, X.; Bandyopadhyay, B.C.; Cheng, K.T. TRPC1: The link between functionally distinct storeoperated calcium channels. Cell Calcium 2007, 42, 213-223. [CrossRef] [PubMed]

24. El Hiani, Y.; Ahidouch, A.; Lehen'kyi, V.Y.; Hague, F.; Gouilleux, F.; Mentaverri, R.; Kamel, S.; Lassoued, K.; Brûlé, G.; Ouadid-Ahidouch, H. Extracellular signal-regulated kinases 1 and 2 and TRPC1 channels are required for calcium-sensing receptor-stimulated MCF-7 breast cancer cell proliferation. Cell. Physiol. Biochem. 2009, 23, 335-346. [CrossRef]

25. Tiruppathi, C.; Ahmmed, G.U.; Vogel, S.M.; Malik, A.B. Ca ${ }^{2+}$ signaling, TRP channels, and endothelial permeability. Microcirculation 2006, 13, 693-708. [CrossRef]

26. Howe, A.K. Regulation of actin-based cell migration by cAMP/PKA. Biochim. Biophys. Acta 2004, 1692, 159-174. [CrossRef] [PubMed]

27. Howe, A.K. Cross-talk between calcium and protein kinase A in the regulation of cell migration. Curr. Opin. Cell Biol. 2011, 23, 554-561. [CrossRef]

28. Whittard, J.D.; Akiyama, S.K. Positive regulation of cell-cell and cell-substrate adhesion by protein kinase A. J. Cell Sci. 2001, 114 (Pt 18), 3265-3272. [CrossRef]

29. Plopper, G.E.; Huff, J.L.; Rust, W.L.; Schwartz, M.A.; Quaranta, V. Antibody-induced activation of beta1 integrin receptors stimulates cAMP-dependent migration of breast cells on laminin-5. Mol. cell Biol. Res. Commun. 2000, 4, 129-135. [CrossRef]

30. Grieshaber, N.A.; Boitano, S.; Ji, I.; Mather, J.P.; Ji, T.H. Differentiation of granulosa cell line: Follicle-stimulating hormone induces formation of lamellipodia and filopodia via the adenylyl cyclase/cyclic adenosine monophosphate signal. Endocrinology 2000, 141, 3461-3470. [CrossRef] 
31. Feoktistov, I.; Goldstein, A.E.; Biaggioni, I. Cyclic AMP and protein kinase A stimulate Cdc42: Role of A(2) adenosine receptors in human mast cells. Mol. Pharmacol. 2000, 58, 903-910. [CrossRef] [PubMed]

32. O'Connor, K.L.; Mercurio, A.M. Protein kinase A regulates Rac and is required for the growth factor-stimulated migration of carcinoma cells. J. Biol. Chem. 2001, 276, 47895-47900. [CrossRef]

33. Dunlap, M.K.; Donaldson, D.J. Effect of cAMP and related compounds on newt epidermal cell migration both in vivo and in vitro. J. Exp. Zool. 1980, 212, 13-19. [CrossRef]

34. Smirnov, V.N.; Antonov, A.S.; Antonova, G.N.; Romanov, Y.A.; Kabaeva, N.V.; Tchertikhina, I.V.; Lukashev, M.E. Effects of forskolin and phorbol-myristate-acetate on cytoskeleton, extracellular matrix and protein phosphorylation in human endothelial cells. J. Mol. Cell. Cardiol. 1989, 21 (Suppl. 1), 3-11. [CrossRef]

35. Goldman, J.E.; Abramson, B. Cyclic AMP-induced shape changes of astrocytes are accompanied by rapid depolymerization of actin. Brain Res. 1990, 528, 189-196. [CrossRef]

36. Rosenberg, G.H.; Alahari, S.K.; Käufer, N.F. prp4 from Schizosaccharomyces pombe, a mutant deficient in pre-mRNA splicing isolated using genes containing artificial introns. Mol. Gen. Genet. MGG 1991, 226, 305-309. [CrossRef]

37. Kojima, T.; Zama, T.; Wada, K.; Onogi, H.; Hagiwara, M. Cloning of human PRP4 reveals interaction with Clk1. J. Biol. Chem. 2001, 276, 32247-32256. [CrossRef]

38. Lützelberger, M.; Käufer, N.F. The Prp4 kinase: Its substrates, function and regulation in pre-mRNA splicing. In Protein Phosphorylation in Human Health; InTech: London, UK, 2012.

39. Long, J.C.; Caceres, J.F. The SR protein family of splicing factors: Master regulators of gene expression. Biochem. J. 2009, 417, 15-27. [CrossRef]

40. Schwelnus, W.; Richert, K.; Opitz, F.; Groß, T.; Habara, Y.; Tani, T.; Käufer, N.F. Fission yeast Prp4p kinase regulates pre-mRNA splicing by phosphorylating a non-SR-splicing factor. EMBO Rep. 2001, 2, 35-41. [CrossRef] [PubMed]

41. Montembault, E.; Dutertre, S.; Prigent, C.; Giet, R. PRP4 is a spindle assembly checkpoint protein required for MPS1, MAD1, and MAD2 localization to the kinetochores. J. Cell Biol. 2007, 179, 601-609. [CrossRef]

42. Huang, B.; Ahn, Y.-T.; McPherson, L.; Clayberger, C.; Krensky, A.M. Interaction of PRP4 with Krüppel-like factor 13 regulates CCL5 transcription. J. Immunol. 2007, 178, 7081-7087. [CrossRef]

43. Gao, Q.; Mechin, I.; Kothari, N.; Guo, Z.; Deng, G.; Haas, K.; McManus, J.; Hoffmann, D.; Wang, A.; Wiederschain, D. Evaluation of cancer dependence and druggability of PRP4 kinase using cellular, biochemical, and structural approaches. J. Biol. Chem. 2013, 288, 30125-30138. [CrossRef]

44. Islam, S.U.; Shehzad, A.; Sonn, J.K.; Lee, Y.S. PRPF overexpression induces drug resistance through actin cytoskeleton rearrangement and epithelial-mesenchymal transition. Oncotarget 2017, 8, 56659. [CrossRef]

45. Islam, S.U.; Ahmed, M.B.; Lee, S.J.; Shehzad, A.; Sonn, J.K.; Kwon, O.S.; Lee, Y.S. PRP4 kinase induces actin rearrangement and epithelial-mesenchymal transition through modulation of the actin-binding protein cofilin. Exp. Cell Res. 2018, 369, 158-165. [CrossRef]

46. Bae-Harboe, Y.S.; Park, H.Y. Tyrosinase: A central regulatory protein for cutaneous pigmentation. J. Investig. Dermatol. 2012, 132, 2678-2680. [CrossRef]

47. D’Mello, S.A.; Finlay, G.J.; Baguley, B.C.; Askarian-Amiri, M.E. Signaling Pathways in Melanogenesis. Int. J. Mol. Sci. 2016, 17, 1144. [CrossRef]

48. Watson, E.L.; Jacobson, K.L.; Singh, J.C.; Idzerda, R.; Ott, S.M.; DiJulio, D.H.; Wong, S.T.; Storm, D.R. The type 8 adenylyl cyclase is critical for Ca2+ stimulation of cAMP accumulation in mouse parotid acini. J. Biol. Chem. 2000, 275, 14691-14699. [CrossRef]

49. Oishi, A.; Makita, N.; Sato, J.; Iiri, T. Regulation of RhoA signaling by the cAMP-dependent phosphorylation of RhoGDI $\alpha$. J. Biol. Chem. 2012, 287, 38705-38715. [CrossRef]

50. Chung, S.; Lim, G.J.; Lee, J.Y. Quantitative analysis of melanin content in a three-dimensional melanoma cell culture. Sci. Rep. 2019, 9, 780. [CrossRef]

51. Peters, A.A.; Simpson, P.T.; Bassett, J.J.; Lee, J.M.; Da Silva, L.; Reid, L.E.; Song, S.; Parat, M.O.; Lakhani, S.R.; Kenny, P.A.; et al. Calcium channel TRPV6 as a potential therapeutic target in estrogen receptor-negative breast cancer. Mol. Cancer Ther. 2012, 11, 2158-2168. [CrossRef]

52. Ding, X.; He, Z.; Zhou, K.; Cheng, J.; Yao, H.; Lu, D.; Cai, R.; Jin, Y.; Dong, B.; Xu, Y.; et al. Essential role of TRPC6 channels in G2/M phase transition and development of human glioma. J. Natl. Cancer Inst. 2010, 102, 1052-1068. [CrossRef]

53. Tsavaler, L.; Shapero, M.H.; Morkowski, S.; Laus, R. Trp-p8, a novel prostate-specific gene, is up-regulated in prostate cancer and other malignancies and shares high homology with transient receptor potential calcium channel proteins. Cancer Res. 2001, 61, 3760-3769.

54. Stewart, T.A.; Yapa, K.T.; Monteith, G.R. Altered calcium signaling in cancer cells. Biochim. Biophys. Acta 2015, 1848 (10 Pt B), 2502-2511. [CrossRef] 